\title{
Effects of timing, intensity and duration of pollination on kernel set and yield in maize (Zea mays L.) under temperate conditions
}

\author{
P.C. STRUIK \& T. MAKONNEN \\ Department of Agronomy, Wageningen Agricultural University, Haarweg 333, NL 6709 RZ \\ Wageningen, Netherlands
}

Received: 18 February 1992; accepted 10 July 1992

\begin{abstract}
Pollen shedding and silking of maize can be desynchronized, which may result in poor grain set. In four field experiments the timing, intensity and duration of pollination was influenced by different types of ear-covering treatments, under ecological conditions in which desynchronization is small. The pollen production already reached a maximum after a few days after the onset of anthesis. After $8-10$ days, $99 \%$ of the pollen was already shed. Tassel treatments hardly affected the grain set, probably because there was ample lateral transport of pollen. Apparently, silks are already receptive directly after extrusion. Covering the ears on different moments after the onset of anthesis resulted in reduced kernel set. This effect was stronger when the covering was earlier, but the effect was also modified by plant density and the environmental conditions. In two experiments, 5 - 6 days of pollination were sufficient to obtain a maximum grain set. In other experiments, the maximum grain set required a longer period of pollination. In the uncovering treatments the pollination was delayed and therefore more silks were exposed to pollen at the same time. A long delay of silk exposure inhibited grain set because of a lack of pollen and a reduced functionality of silks. In one experiment, a short delay of pollination slightly increased the number of kernels per ear, because of a positive effect on the grain set in the top of the ear. A long delay in pollination affected the distribution of dry matter over the ear, even when it did not reduce overall grain set. There was a strong relation between the proportion of grain set and the ear yield in all experiments. Only in one experiment, the maximum ear yield could already be obtained with a significantly reduced grain set. Under Dutch conditions, pollen is usually abundantly available for a proper grain set. Only in the upper part of the ear, grain set can be limited by lack of pollen. The silks remain functional for such a long time, that their receptiveness is not limiting either.
\end{abstract}

Keywords: anthesis, pollen shedding, pollination, silking, pollen shedding-silking interval, grain set, plant density, Zea mays L.

\section{Introduction}

Maize (Zea mays L.) is a monoecious plant with the staminate inflorescence (the 'tassel') on top of the main stem and with one or more pistillate inflorescences (the 


\section{P.C. STRUIK AND T. MAKONNEN}

'ears') on top of lateral branches in the axils of the leaves in the mid-section of the main stem.

Under normal climatic conditions of the main grain-maize growing areas of the world, the tassel sheds its first pollen ('anthesis') before the upper ear starts to extrude the styles of the pistils (also called 'silks' and therefore the process of extrusion of these styles is called 'silking'). This phenomenon is called protandry. When protandry is large and the duration of pollen shedding is short, pollen will not be abundant when the silks are present. This will especially affect the florets in the top of the ear, because their silks emerge later than those of the lower florets (Tollenaar \& Daynard, 1978a). Sadras et al. (1985a) observed that a density of about 5 pollen grains per silk was necessary to ensure pollination of $90 \%$ of the exposed silks.

The protandry is usually described in terms of the pollen shedding-silking interval. Struik et al. (1986) defined 'desynchronization' as the time lag between the start of silking and the start of pollen shedding, desynchronization given a plus sign in the case of protandry. A large desynchronization is undesirable. It means that fewer pollen grains are available when silks are present to intercept them.

The dynamics of pollen shedding and silk emergence are influenced by environmental conditions, such as temperature (in the normal range, but with extreme effects of both cold and heat; Struik, 1983a, b; Struik et al., 1986), photoperiod (Struik, 1982, 1983c; Struik et al., 1986), light intensity (Struik, 1983d), water stress (Moss \& Downey, 1971; Hall et al., 1980, Herrero \& Johnson, 1981; Hall et al., 1982; Dow et al., 1984; Sadras et al., 1985a, b; Struik et al., 1986), plant density (Buren et al., 1974; Dow et al., 1984), and defoliation (Tollenaar \& Daynard, 1978b). Also genotype has a large effect (Buren et al., 1974; Bertin et al., 1976; Hall et al., 1982), especially when photoperiod-sensitive genotypes are grown under long days.

The gap between pollen shedding and silk extrusion usually widens when plants are exposed to stress before anthesis, since silking tends to be delayed more than anthesis. Thereby stress reduces the possibilities for pollination. This problem is enhanced by the negative effect of stress on the elongation of the highest stem internodes and the peduncle, resulting in more interception of pollen by the leaves and by the fact that maize pollen is rather heavy and it needs a considerable air flow to get cross-pollination. When air flow is considerable, cross pollination occurs and chances of pollination improve due to the plant-to-plant variability in time of anthesis.

Protandry reflects the history of organ development and the organ interactions between tassel and ears. Ears are usually initiated a few days after the tassel (Fuchs, 1968). From tassel initiation until the end of pollen shedding the tassel competes with developing ears for nutrients and photosynthates (Duncan et al., 1967). A strong apical dominance of the tassel over the ears delays and retards the growth of the ear (Muleba et al., 1983; Struik et al., 1986). This apical dominance is reinforced by environmental stress (Phillips, 1975).

Desynchronization does not always have a positive value. Under certain conditions the desynchronization can be smaller than zero, meaning that silking starts before anthesis. Negative desynchronization is also called protogyny. Protogyny is 
stimulated by average temperatures of approximately $15^{\circ} \mathrm{C}$ (Struik, 1982, 1983a; Struik et al., 1986), a photoperiod shorter than the critical photoperiod (Struik, 1982, 1983c) and high light intensity (Struik, 1983d). Protogyny frequently occurs under field conditions in north-west Europe, because the temperatures are low and the adapted genotypes are rather day neutral. However, a strong protogyny is undesirable, because it is associated with rapid ear development, resulting in a low number of spikelets per ear (Struik et al., 1986).

Based on Fig. 6 of Struik et al. (1986), a poor synchronization of pollen shedding and silking can affect the grain set, because:

- pollen shedding is already finished before (all) silks have emerged

- the amount of pollen is not adequate to pollinate all the silks (see also Sadras et al., 1985a)

- silks are not receptive yet when pollen is shed

- silks are not receptive anymore when pollen is shed

- pollen is not viable when receptive silks are present.

Under the conditions prevailing in the Netherlands, desynchronization ranges from minus a few days to plus a few days. Effects of restricted pollination may therefore be different from those described in literature. We will describe and discuss the possibilities mentioned on the basis of experimental data on the effects of restricted pollination (either in time, in amount or both) on the success of pollination and ear yield.

\section{Materials and methods}

General procedures of crop husbandry

Four experiments were carried out in the field. Experiments 1, 2, and 3 were laid out on a heavy river clay soil, whereas experiment 4 was on a very light, gravelly sandy soil. The crops were treated as normal forage-maize crops with proper crop protection, fertilizer supply and sprinkler irrigation when necessary. Only in 1990, some drought occurred after flowering. Row distance was $75 \mathrm{~cm}$ in all experiments. Details on the cultural practice and some relevant crop data are presented in Table 1. Details on the treatments and measurements are described below.

\section{Details on experiments}

Experiment 1. Flowering dates were recorded every other day by assessing the proportion of plants showing pollen shedding or silking $(n=40)$. On days $0,2,4,5,6$, or 7 after onset of anthesis, ears were covered with paper bags to prevent pollination. On each date two replications, consisting of one row of 25 plants were treated. Two plots remained untreated.

The experiment was laid out as a randomized block design. The crop in which the experiment was laid out was very uniform.

Experiment 2. In this experiment pollen production nor dynamics of flowering were recorded. The experiment was laid out as a split-plot design in three replications, 


\section{P.C. STRUIK AND T. MAKONNEN}

Table 1. Some details on the materials and methods and on crop development of experiments 1-4.

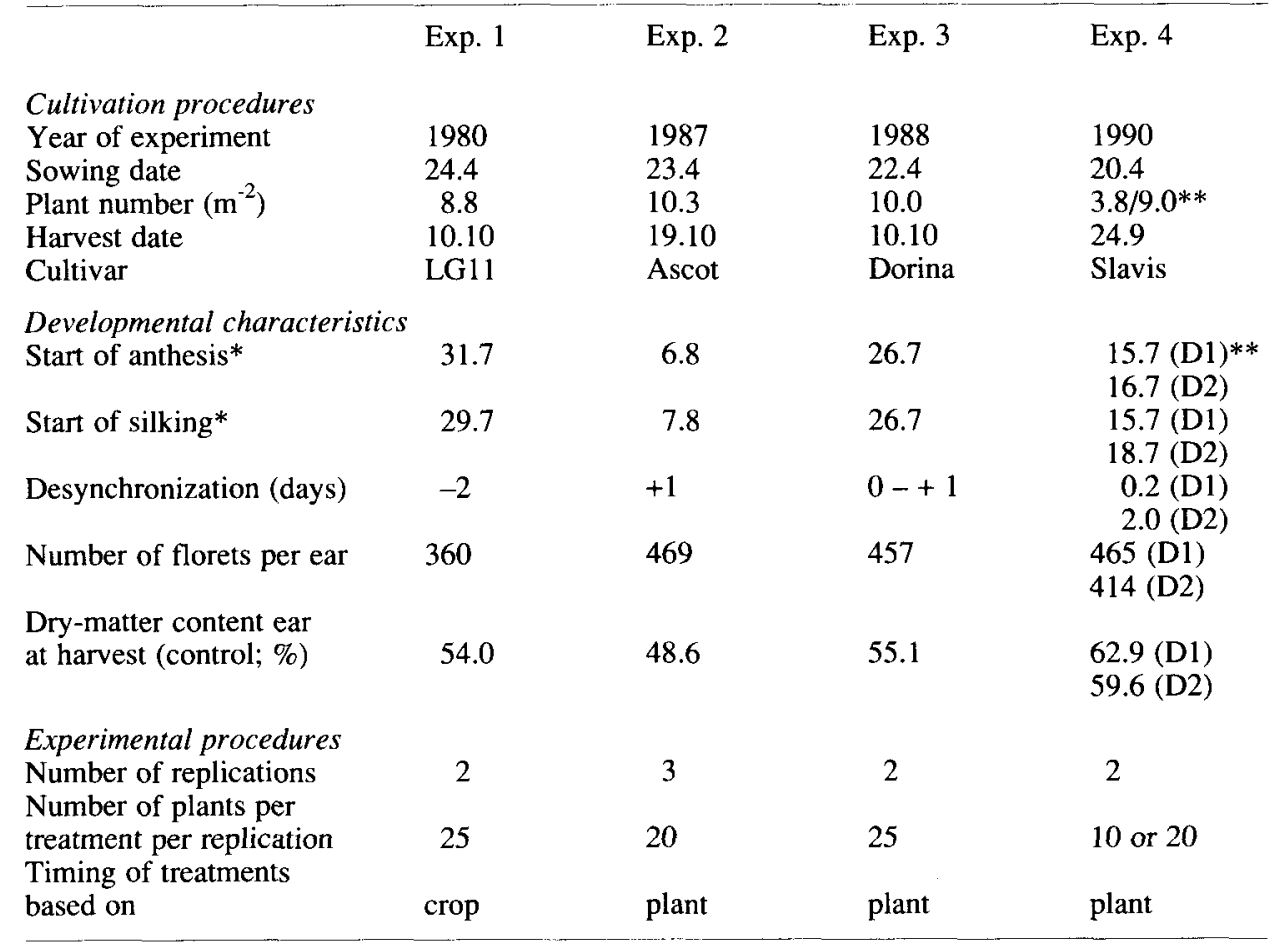

* First plants in the crop flowering .** D1 = density of 3.8 plants $\mathrm{m}^{-2}$; $\mathrm{D} 2=$ density of 9.0 plants $\mathrm{m}^{-2}$

with tassel treatments as main factor and ear treatments as split factor. Each plot consisted of 6 rows of $5 \mathrm{~m}$. Tassel treatments were carried out for the entire plot, whereas only plants on the inner two rows were used for measurements.

The following tassel treatments were applied:

T1: tassels were removed at tassel emergence.

T2: tassels were removed at the onset of anthesis.

T3: the main axis of the tassel was removed when $75 \%$ of its spikelets were shedding pollen.

T4: the tassel branches were removed at the onset of anthesis.

T5: tassels remained untreated.

Tassel treatments were carried out to reduce the pollen availability and to reduce the apical dominance of the tassel over the ears. Because there was sufficient lateral movement of pollen, pollen availability was hardly affected.

The following ear treatments were applied:

C1: Ears were covered before the silks emerged.

C2: Ears were covered when silks had reached a length of $4 \mathrm{~cm}$.

C3: Ears were covered when silks had reached a length of $8 \mathrm{~cm}$.

C4: Ears were not covered. 
Ears were covered using paper bags, which were removed when anthesis was completed.

Because the plant-to-plant variability was large in this crop, plants were checked daily and both tassel and ear treatments were carried out per single plant when it had reached the proper stage.

At final harvest 20 plants were harvested from the inner rows.

Experiment 3. The experiment consisted of two parts: recording pollen shedding and assessing effects of the duration of pollination on grain set. Pollen shedding was recorded on 36 tassels, which were cut off before the onset of anthesis and transferred to a greenhouse (temperature: $18^{\circ} \mathrm{C}$ during the day and $12{ }^{\circ} \mathrm{C}$ during the night) and put on water. These tassels were enclosed in paper bags to collect the pollen. The amount of pollen was recorded once every two days and the pollen production per day and the cumulative proportion of total pollen production were calculated. In the graphs, the data on daily production are alloted to the days between the days of measurements, whereas the data on cumulative proportion of total pollen production were assigned to the days of record.

The experiment was a randomized block design with two replications and with two types of treatments:

a) Ears were covered with paper bags on days $0,2,4,6,8,10$, or 12 after the onset of anthesis. Plants were checked individually for the proper timing of the treatment. Only plants with a desynchronization of 0 to +1 day were used.

b) Ears were covered on day 0 and the paper bags were removed on days $0,3,6,9$, 12,15 , or 18 after the onset of anthesis. Similar selection took place as mentioned under a.

Each plot consisted of 25 plants with sufficient guard rows surrounding each plot. After anthesis was completed the bags were removed from all ears.

Experiment 4. Two plant densities ( 3.8 and 9.0 plants $\mathrm{m}^{-2}$ ) were realized by thinning the crops to the right stand shortly after emergence. Each plot consisted of 4 rows of $2 \mathrm{~m}$, with a border row at each side. The experiment was laid out as a split- plot design with the plant density as main factor and the ear treatments as split factor.

Pollen production was recorded by enclosing 15 tassels per plant density in the field. Pollen was collected every two days and weighed. Data presentation is done in the same way as indicated for experiment 3.

For each plant density the following ear treatments were realized on selected plants:

a) Ears were covered with paper bags on days 1, 5, 7, or 9 after the onset of anthesis.

b) Ears were covered before the start of anthesis and paper bags were removed on days $1,5,7$, or 9 after the onset of anthesis.

c) Ears remained untreated.

For each plant density, plants were selected that showed a desynchronization of 0 days. Each single plant was treated when it had reached the proper stage.

After anthesis was completed the bags were removed. Ten (treated plants) or 20 plants (control plots) were harvested per treatment per replication. 


\section{P.C. STRUIK AND T. MAKONNEN}

\section{Measurements}

In all experiments only the top ears were harvested. The lower ears usually did not develop well-filled kernels. Ears were harvested and stored at a temperature of $2{ }^{\circ} \mathrm{C}$ during further processing. The number of unfertilized florets of aborted kernels and the number of well-filled kernels were counted. Since the number of aborted kernels was usually very low, they were added to the number of well-filled kernels to give the total number of kernels. The total number of florets + kernels usually did not differ significantly among treatments of the same experiment. In experiment 3 , there was a significant difference of $14 \%$ between the two extremes of the "covering treatments', caused by an unfortunate randomization; the other treatments did not differ significantly in total number of florets + kernels. In experiment 4 , there was a significant effect of the plant density (see Table 1 ). In experiment 3 , the grain set was also recorded for different sections of the ear separately.

Total fresh weights of the ears per plot were assessed, the ears were chopped and the dry-matter content was determined on a subsample of ca $500 \mathrm{~g}$ of fresh weight by drying in a forced ventilated oven at $70^{\circ} \mathrm{C}$ (experiment 1 ) or $105{ }^{\circ} \mathrm{C}$ (experiments 2 , 3 , and 4) until constant weight and subsequent re-weighing. In experiment 4 , ears were divided into three parts of equal length to assess the dry-matter partitioning within the ear.

Results were subjected to a standard analysis of variance. In the figures, presenting the effects on number of kernels per ear, the protected least significant differences (PLSD; $\alpha=0.05$ ) are indicated (Snedecor \& Cochran, 1980). Data on the relative grain set were transformed to arcsin of the square root of the percentage before analysis. Therefore, instead of presenting PLSD values, significant differences are indicated by letters in the figures, presenting the effects on relative grain set.

\section{Results}

\section{Dynamics of flowering}

The flowering dynamics are illustrated in Fig. 1a (exp. 1), Fig. 1b (exp. 3) and Fig. 1c (exp. 4). Because flowering data were not normally distributed, a probit analysis was not carried out.

Experiment 1. Anthesis started later than silking, resulting in a desynchronization at $50 \%$ flowering of -2 days. One hundred percent flowering was reached within 2 weeks.

Experiment 2. Plants varied greatly in flowering dates. Since the plants were treated individually this did not affect the quality of the experiment. It resulted, however, in a long period of pollen availability (approx. 20 days), and therefore the effects of the tassel treatments were reduced. In experiment 2 , protandry was observed with a desynchronization of +1 day (data not shown). 

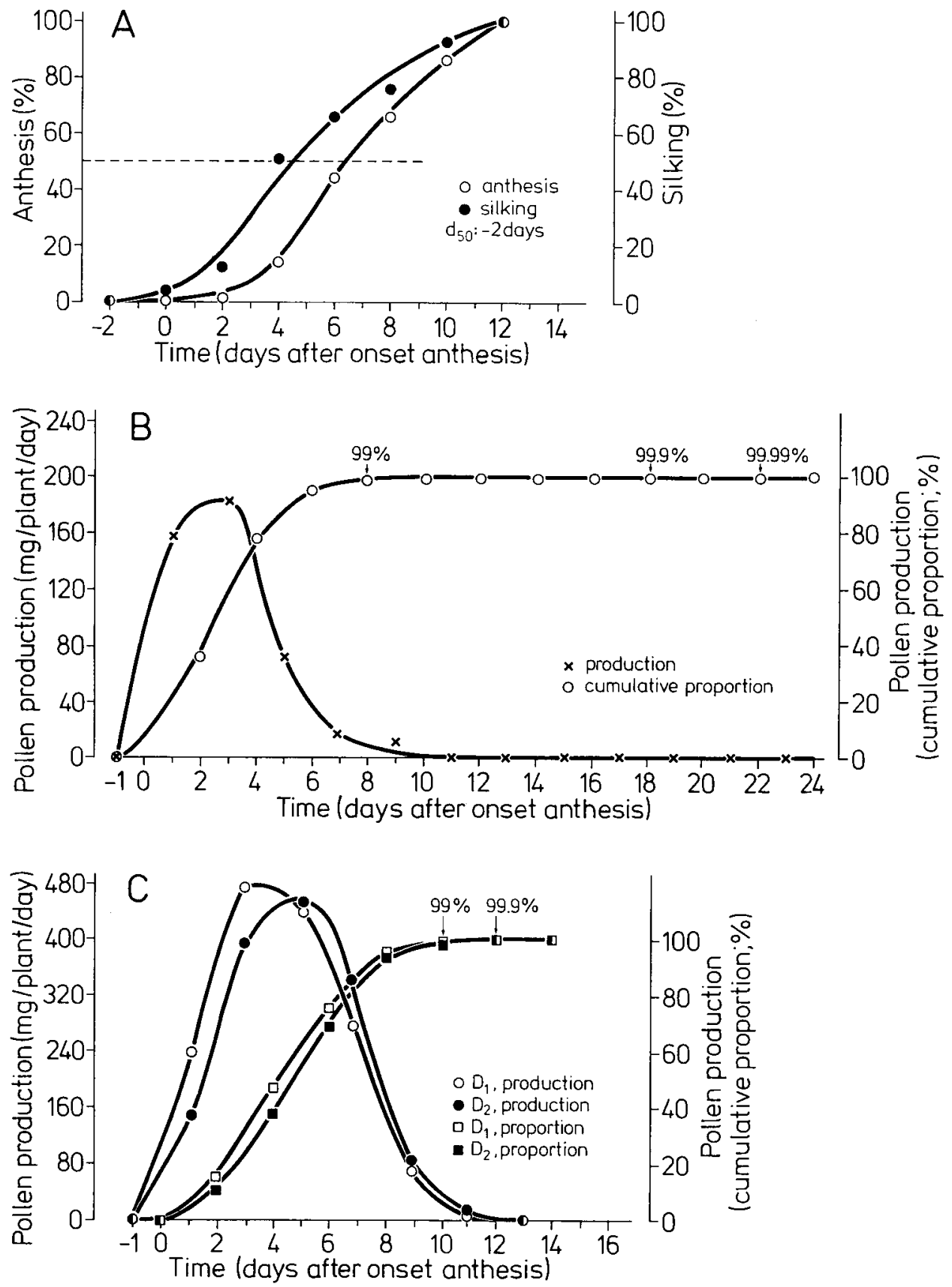

Fig. 1. Dynamics of anthesis in experiment 1 (A), experiment 3 (B) and experiment 4 (C). In experiment 4 , two plant densities were present: D1 $\left(3.8\right.$ plants $\left.\mathrm{m}^{-2}\right)$ and D2 $\left(9.0\right.$ plants $\left.\mathrm{m}^{-2}\right)$. 
Experiment 3. Figure $1 \mathrm{~b}$ shows that $99 \%$ of the pollen was shed within the first 8 days after the onset of anthesis. The total amount of pollen produced was lower than normal (see also Fig. 1c), probably because of the removal of the tassel from the plants. The development of pollen shedding over time and its duration, however, more or less reflected the situation on intact plants in the field.

Experiment 4. Differences in flowering characteristics between densities were small, but highly significant ( $\mathrm{P}$ usually $<0.01$ ). Plant densities hardly differed in timing of the onset of pollen shedding (difference approx. 1 day). There was also hardly any effect on the course of pollen shedding over time. The lower plant density produced slightly more pollen during the first days of anthesis than the higher density, and it reached its maximum earlier, but the maximum rate of pollen shedding was similar, as were the total amounts of pollen produced ( $2.95 \mathrm{~g}$ per tassel for 3.8 plants $\mathrm{m}^{-2}$ and $2.86 \mathrm{~g}$ per tassel for 9.0 plants $\mathrm{m}^{-2}$ ), the duration of pollen shedding and the moment of $99 \%$ pollen shed.

These data are based on selected plants and corrected for the onset of anthesis. The plant-to-plant variation in timing of flowering prolonged the period of pollen availability to 18 days in both densities and resulted in more pollen becoming available during the second half of the pollination period than could be expected based on the data of the individual plants. This observation is relevant for the explanation of the small effects of the late uncovering treatments on the grain set (see below).

\section{Percentage grain set and number of kernels per ear}

Results of grain set and number of kernels per ear are illustrated in Table 2 and Figs $2,3,4$, and 5 .

Experiment 1 . In this uniform and rapidly developing crop, it took only 6 days to reach the maximum proportion of grain set or the maximum number of kernels (Fig.

Table 2. Effect of tassel and ear treatments on the proportion of grain set (in \%) in experiment 2. For treatment codes see Materials and methods. Means followed by a different letter are significantly different at $\mathrm{P}<0.05$.

\begin{tabular}{|c|c|c|c|c|c|}
\hline \multirow[t]{2}{*}{ Tassel treatment* } & \multicolumn{4}{|c|}{ Ear treatments } & \multirow[t]{2}{*}{ Average } \\
\hline & $\mathrm{Cl}$ & $\mathrm{C} 2$ & C3 & $\mathrm{C} 4$ & \\
\hline $\mathrm{T} 1$ & 6.2 & 31.8 & 43.9 & 89.9 & 42.9 \\
\hline $\mathrm{T} 2$ & 19.0 & 31.5 & 57.8 & 91.1 & 49.8 \\
\hline T3 & 10.3 & 43.7 & 52.9 & 89.2 & 49.0 \\
\hline$T 4$ & 12.8 & 36.7 & 49.9 & 91.9 & 47.8 \\
\hline T5 & 8.0 & 36.9 & 55.6 & 89.1 & 47.4 \\
\hline Mean & $11.2 \mathrm{a}$ & $36.1 \mathrm{~b}$ & $52.0 \mathrm{c}$ & $90.2 \mathrm{~d}$ & \\
\hline
\end{tabular}

* Effect of tassel treatments significant at $P=0.074$. Interaction between tassel and ear treatments not significant. 

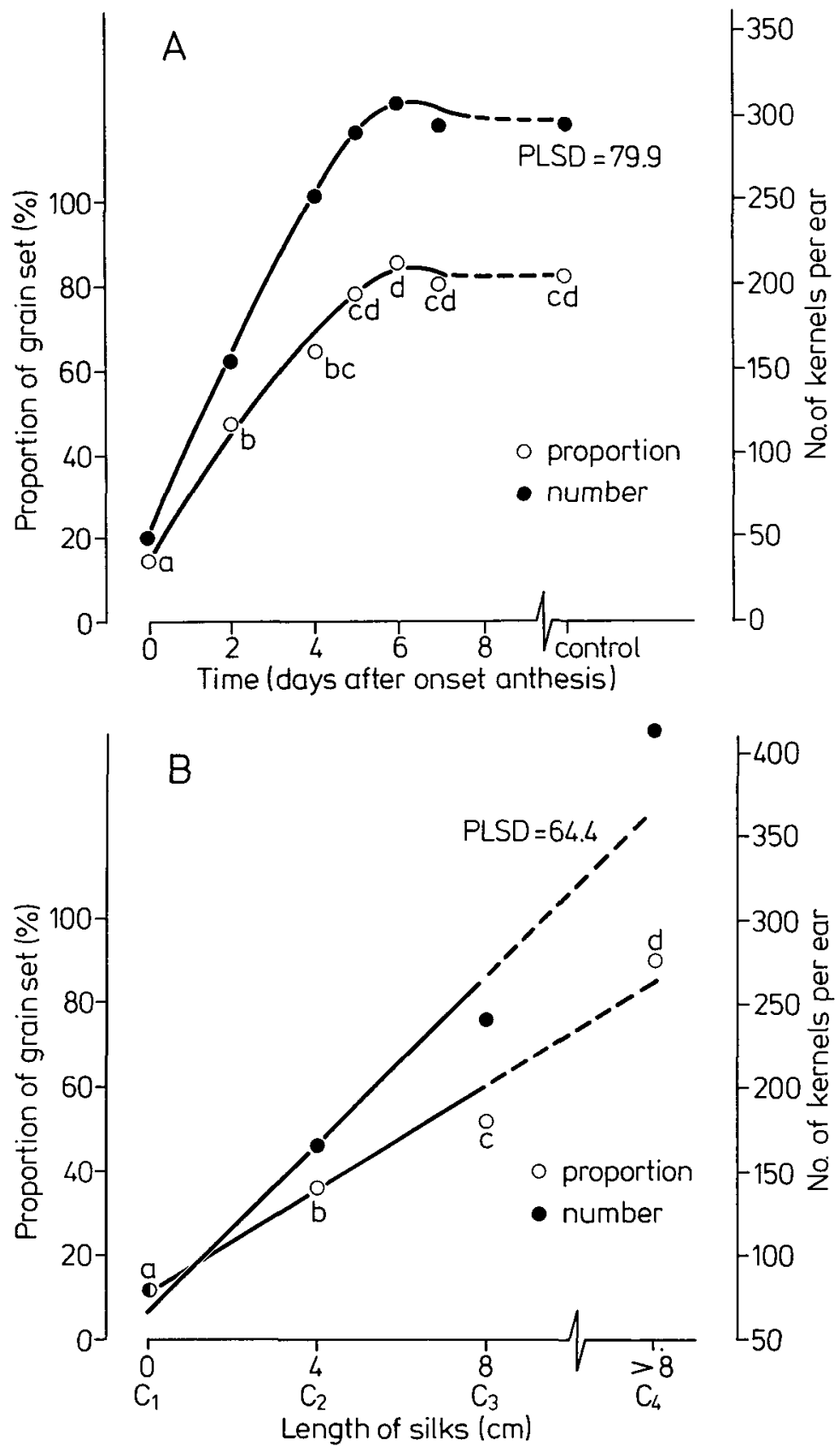

Fig. 2. Effect of time of ear covering, expressed in days after onset anthesis for experiment 1 (A) or in length of the silks already extruded for experiment 2 (B) on the relative grain set and the number of kernels. PLSD $=$ protected least significant difference $(\alpha=0.05)$ for data on kernel number. Grain set values with different letters are significantly different $(\alpha=0.05)$. 
2a); plants covered after 5 days after the onset of anthesis already showed grain set similar to the control treatment. This early maximum can partly be explained by the protogyny which made sure that there were already many silks available when anthesis started.

Experiment 2. Tassel treatments hardly affected the proportion of grain set (effect only significant at $\mathrm{P}=0.074$; Table 2 ), probably due to lateral movement of pollen. Even the most rigid treatment $\mathrm{T} 1$ had a minor effect. This effect was probably not caused by lack of pollen, since in that case also treatment $\mathrm{T} 2$ should have shown similar effects. The effect of the tassel treatments on the number of kernels per ear was larger $(\mathrm{P}<0.05$; data not shown; again only $\mathrm{T} 1$ resulting in a lower number of kernels than the other tassel treatments), but in this case there was also a very significant $(P<0.001)$ interaction between the tassel and ear treatments.

The effect of the ear treatments (averaged over the tassel treatments) on the proportion of grain set and the number of kernels per ear is shown in Fig. 2b. There was a continuous increase in kernel set when the covering was delayed. Since pollen was already abundantly available (compare desynchronization in Table 1 and Fig. 1b), this effect must be caused by an increase in the receptiveness of the silks and/or in the number of silks extruded before covering.

Experiment 3. In experiment 3 covering had to be delayed much longer to reach the maximum proportion of grain set in the whole ear (Fig. 3a). In fact the maximum was never reached. For the lower and middle part of the ear, the maximum grain set, however, was already obtained when covering was delayed until 6 days after onset of anthesis. The silks of the upper part were extruded much later than those of the lower parts. They could therefore not be pollinated when covering was early, but grain set in this part was continuously increased when covering was delayed. This is explained by the availability of pollen and of silks before the early covering.

The effects of uncovering are shown in Fig. 3b. When the ears were uncovered shortly after the onset of anthesis, the proportion of grain set was slightly lower than when uncovering took place several days later. This effect was completely caused by a better grain set in the top of the ear at later uncovering. A maximum grain set was obtained when uncovering was delayed until 3 to 9 days after onset of anthesis. This effect is probably caused by the competition within the ear for assimilates during and shortly after fertilization of the individual florets. When the lower, dominant florets cannot profit from their advantage because of a delay in pollination, the dominated ones have a better chance to survive. Later uncovering reduced the grain set in all ear parts, but the effects were significantly smaller in the upper part than in the middle or lower parts of the ear. Especially on day 15 there was an obvious difference $(\mathrm{P}<$ 0.05 ) between ear parts in favour of the upper part. At this time both the receptiveness of the silks and the availability of pollen played a role. The youngest part of the ear still contained florets that could well be fertilized, whereas the functionality of the florets in the rest of the ear was already declining. The receptiveness of the silks lasted at least 9 days in this experiment but some of the silks could remain functional for over 2 weeks. 

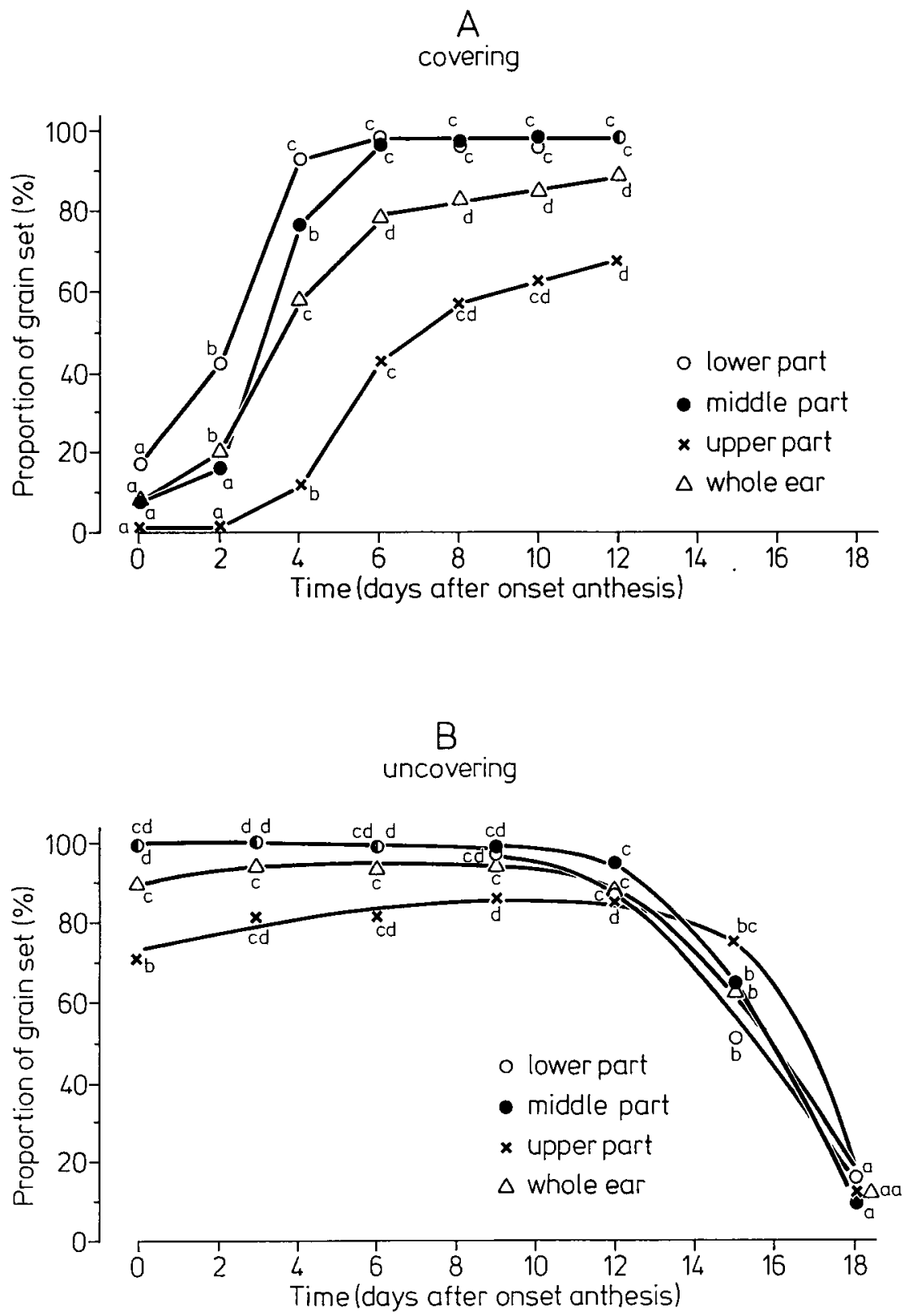

Fig. 3. Effect of time of ear covering (A) or uncovering of the ear (B) on the proportion of grain set in several sections of the ear in experiment 3. Different letters indicate significant differences within ear parts at $\alpha=0.05$. 


\section{P.C. STRUIK AND T. MAKONNEN}

The poor grain set after uncovering on day 18 was mainly due to lack of pollen. This was also visible from the spread of grain set over the entire ear.

The duration of pollination was estimated to last 19 days. This estimation makes it possible to compare the covering and uncovering treatments on a common basis (Fig. $4 a, b, c$ and d). When the number of kernels on the lower part is plotted against the duration of pollination, it is obvious that the covering treatments had a better grain set when they were only exposed to a few days of pollination than the uncovering, simply because the amount of pollen per day was higher during the first days of anthesis than during the last days of pollination. The two lines in Fig. 4a cross each other around day 8. After that the uncovering treatments were more successful, because they had more silks exposed to the pollen. There was even an optimum at day 10 and 13 , caused by the lack of competition with the upper kernels.

For the mid-section of the ear, the patterns for the covering and uncovering treat-
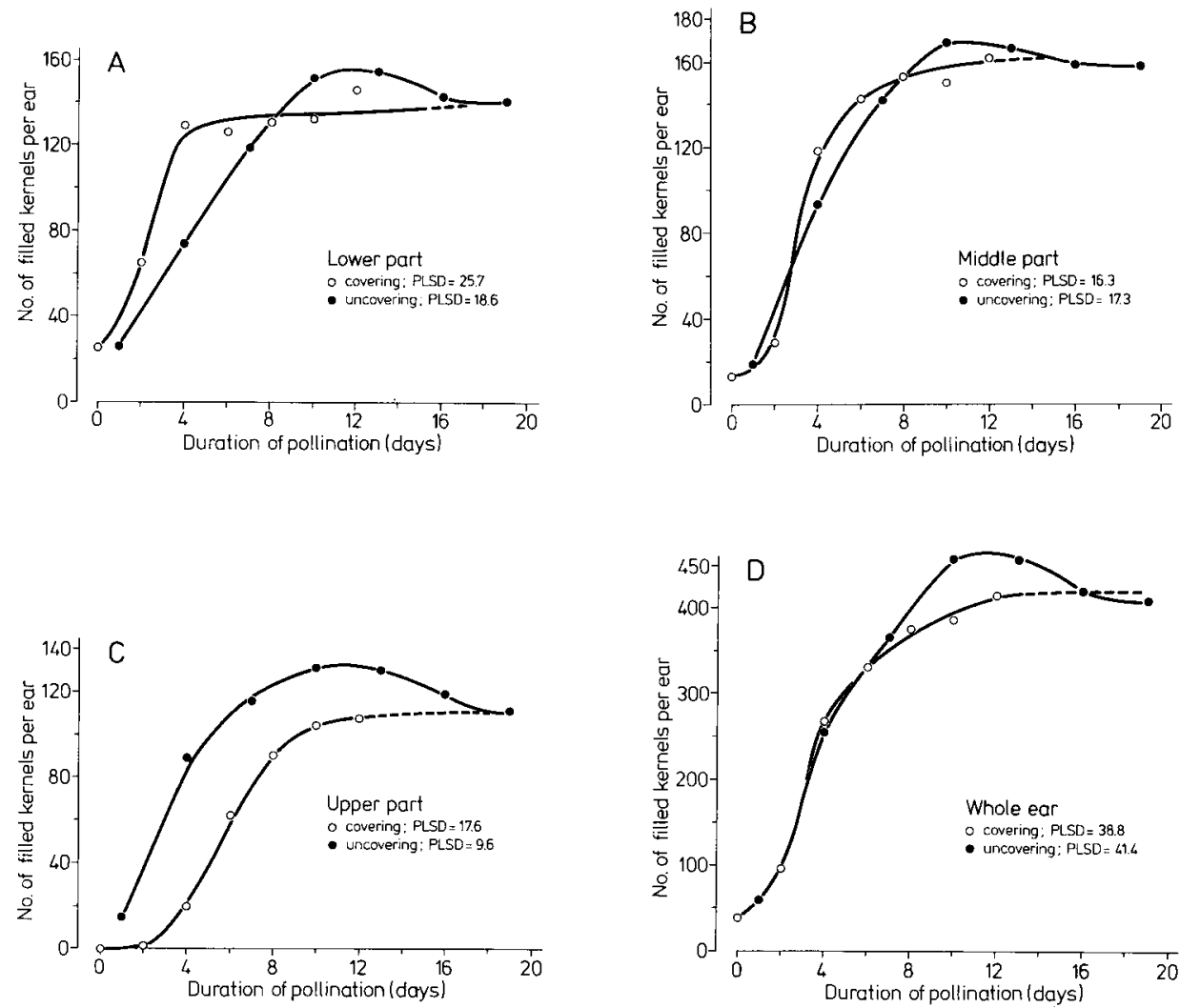

Fig. 4. Effect of duration of pollination on the number of kernels of the lower part of the ear (A), the middle part of the ear (B), the upper part of the ear (C), and of the whole ear (D) for the covering and uncovering treatments in experiment $3 . \mathrm{PLSD}=$ protected least significant difference $(\alpha=0.05)$ for comparisons within ear parts. 
ments were more similar, although some of the effects observed for the lower ear parts were still visible as trends (Fig. 4b).

For the upper ear part (Fig. 4c), the uncovering was always higher than the covering treatment with the same duration of pollination, caused by the positive effect of grain set for the youngest florets when the fertilization of the older florets was delayed.

In all ear parts the lines tend to come together again. Of course with an undisturbed pollination (either by a very early uncovering or a very late covering), there should be no difference between the two types of treatments.

Figure $4 \mathrm{~d}$ gives the relations for the entire ear. The positive effect of a delay of pollination on the performance of the upper florets was still visible, but there were no differences between covering and uncovering treatments when the pollination lasted shorter than 6 days.

Experiment 4. Because there were hardly any differences in the dynamics of pollen shedding, the plants that were covered early responded similarly in both densities (Fig. 5a). When plants were covered after day 7 or later, differences between densities became obvious: the lower density showed a much higher proportion of grain set but needed a longer period of pollination to reach that maximum, because of a larger variation in moment of extrusion of the individual silks in these larger ears and a lower amount of pollen per square metre. The effects of the higher density were very similar to the ones observed in experiment 1.

In contrast to experiment 3 , there was no effect of the timing of uncovering of the ears on the grain set (Fig. 5). However, there was a considerable effect of plant density, which was similar to the one reported for the late covering treatments.

Trends in the number of kernels per ear (Fig. 5b) reflected the differences in proportion of grain set and number of florets per ear (see Table 1). Differences between densities could partly be due to the mild drought which affected the higher plant density more than the lower one.

Figure 6 shows the dry-matter partitioning within the ears for the different treatments. A longer pollination resulting from a later covering decreased the relative yield of the lower part, but increased the proportion of the middle (maximum reached at 5 days pollination) and the upper (maximum reached at 9 days pollination) parts in both densities (Figs 6a and 6c). Absolute yield in the lower parts was fairly stable. Only the duration of 1 day reduced it significantly. The uncovering treatments hardly differed at the lower density (Fig. 6b). At 9.0 plants $\mathrm{m}^{-2}$ there was a gradual decline in the proportion of the upper part the longer the pollination lasted (Fig. 6d), even though the total number of kernels did not differ (Fig. 5b).

\section{Relation between proportion of grain set and ear yield}

The relations between the proportion of grain set and the ear yield at final harvest are illustrated in Fig. 7a (experiment 1), Fig. 7 b (experiment 2), Fig. 7c (experiment 3), and Fig. 7d (experiment 4). 

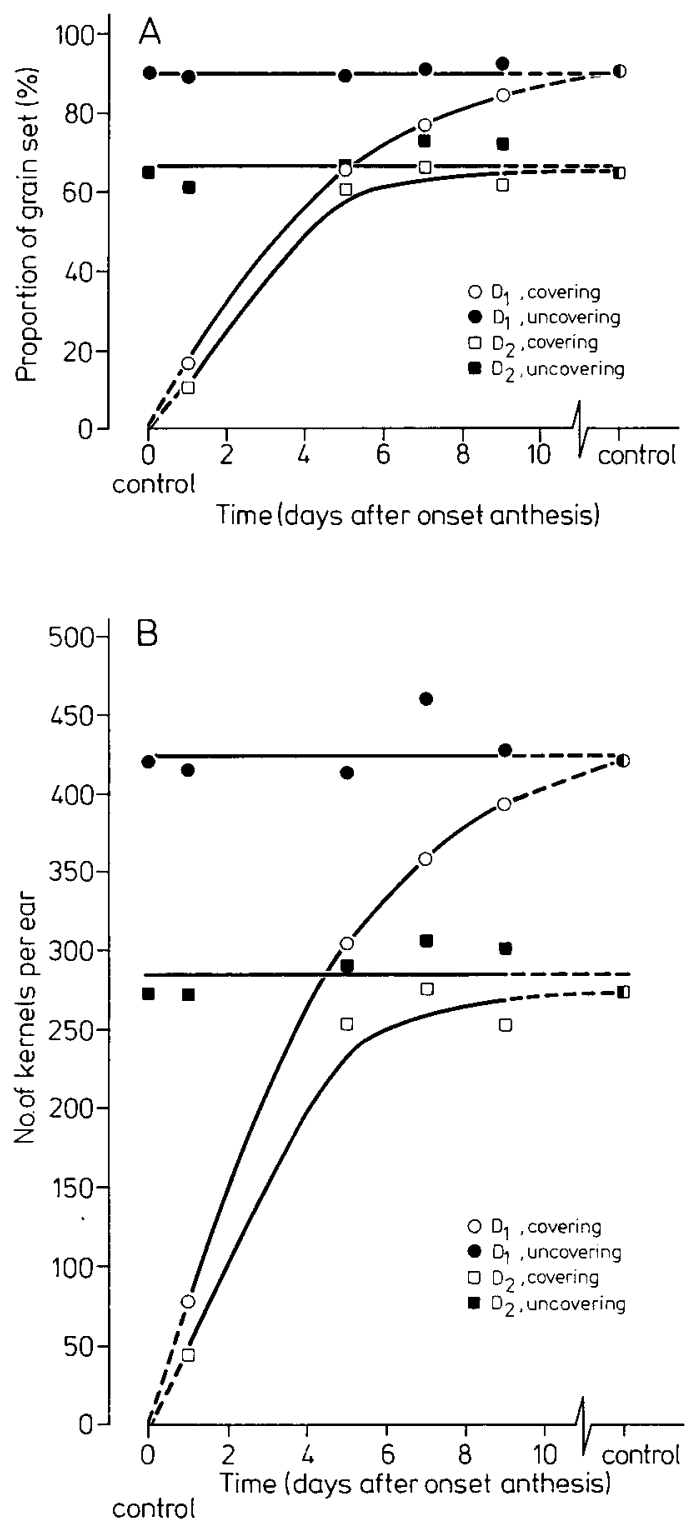

Fig. 5. Effect of time of covering or uncovering of the ear on the proportion of grain set (A) and the number of kernels per ear (B) for a crop with a low plant density (D1; 3.8 plants $\mathrm{m}^{-2}$ ) and a crop with a high plant density (D2; 9.0 plants $\mathrm{m}^{-2}$ ) in experiment 4 . The density effects were significant at $P<0.05$. The interactions between density and ear treatments were also significant: $P<0.05$ for the proportion of grain set (after transformation); $\mathrm{P}<0.001$ for the number of kernels per ear. Because of this interaction, range tests for differences between ear treatments were not carried out. 

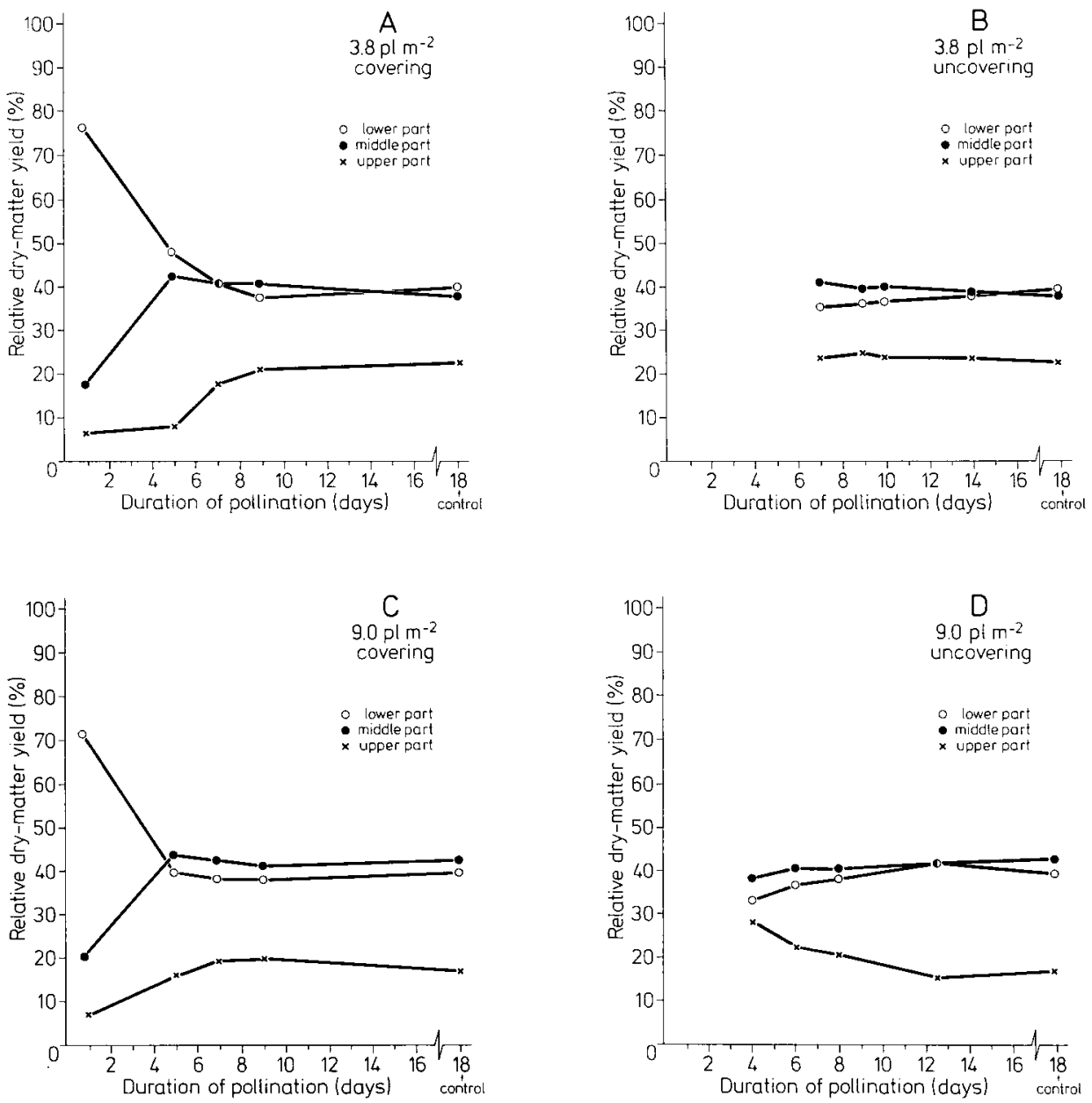

Fig. 6. Effect of the duration of pollination on the relative dry-matter yield (calculated as the dry-matter yield of an ear fraction divided by the dry-matter yield of the entire ear $\times 100 \%$ ) for the lower, middle and upper one-thirds of the ear in experiment 4. A: low plant density, covering; B: low plant density uncovering; $\mathrm{C}$ : high plant density covering; $\mathrm{D}$ : high plant density uncovering.

Experiment 1 . The linear correlation between proportion of grain set and ear yield was very good. For each percentage of increase in grain set the yield increased with $0.92 \mathrm{~g} \mathrm{plant}^{-1}$.

Experiment 2. With very high grain sets, possible when pollination was not disturbed, plants could not fully profit from the extra sink capacity available. This was partly caused by the limitations of the source due to low light intensity during autumn, but also to the large size of the kernels on the lower part of the ears in this 

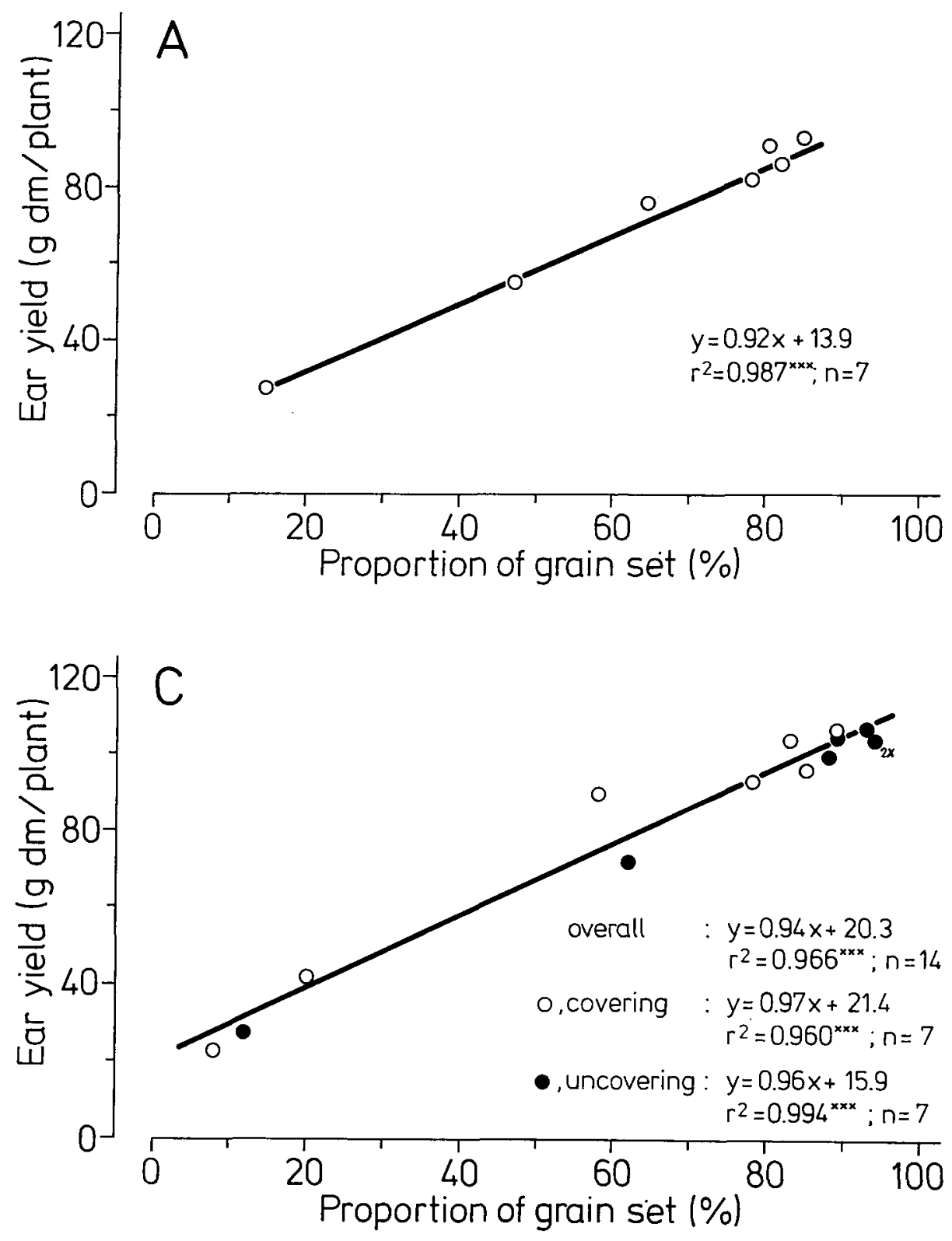

Fig. 7. The relation between ear yield and the proportion of grain set for experiment 1 (A), experiment 2 (B), experiment 3 (C), and experiment 4 (D). In Fig. 7B, the codes refer to the ear-covering treatments (see Materials and methods). In Fig. $7 \mathrm{C}$, the covering and uncovering treatments are distinguished. In Fig. 7D, different symbols are used for the two plant densities (DI $=3.8$ plants $\mathrm{m}^{-2} ; \mathrm{D} 2=9.0$ plants $\mathrm{m}^{-2}$ ) and for the covering and uncovering treatments. 
EFFECTS OF TIMING, INTENSITY AND DURATION OF POLLINATION IN MAIZE
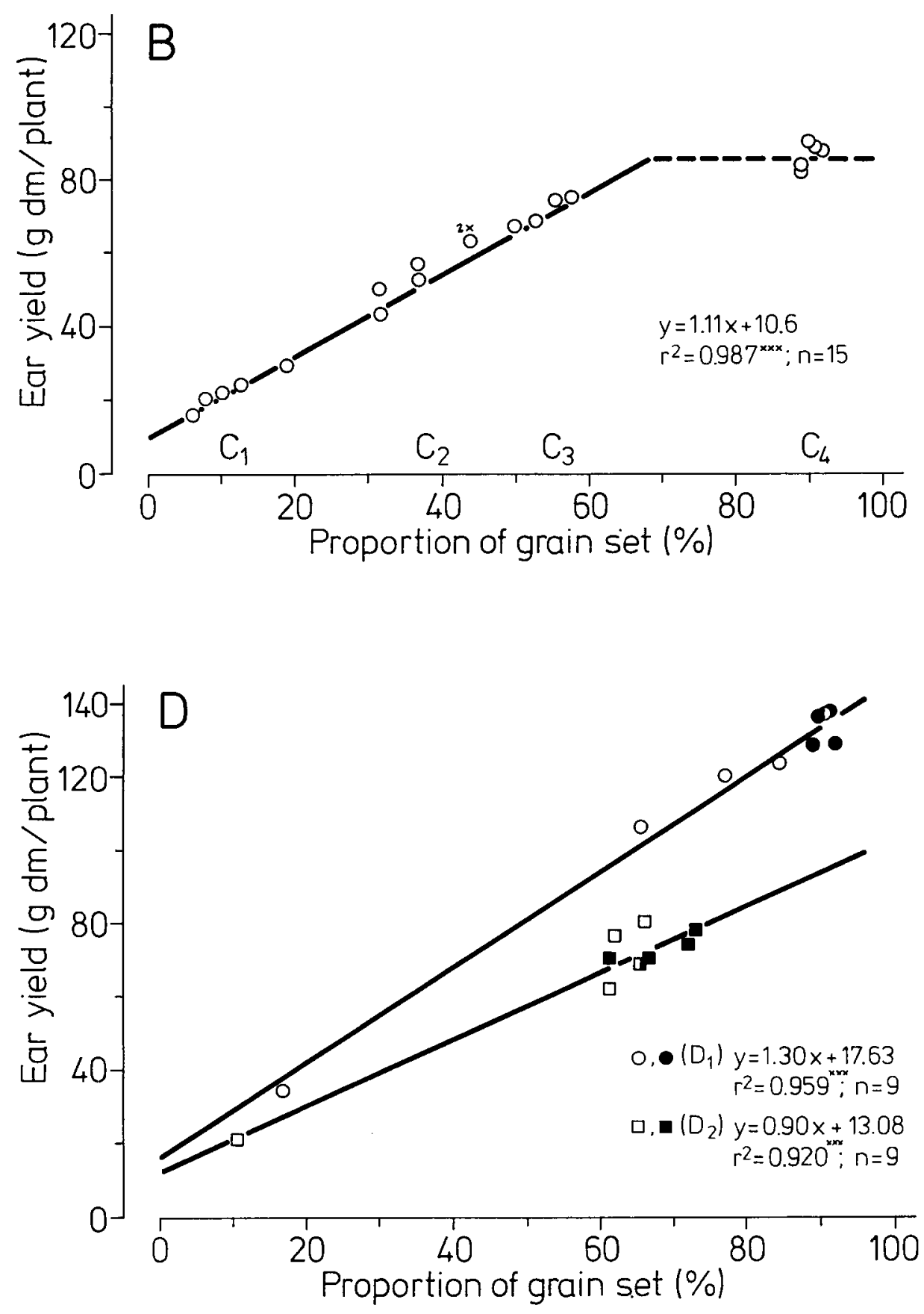

Fig. 7. Continued. 
experiment. This is illustrated by the much higher regression coefficient for the range of 5 to $65 \%$ grain set as compared to experiment 1 .

Experiment 3 . The uncovering and covering treatments fitted the same linear regression rather well. The yield increase per increase of proportion of grain set was very similar to the one reported for experiment 1 . When the linear regression line is determined for covering and uncovering treatments separately, the two lines have the same regression coefficient but differ slightly in intercept. At the same level of grain set, uncovering treatments started grain filling later than covering treatments.

Experiment 4. In this experiment the measurements were not well distributed over the entire range of grain set. Therefore the regression should be considered with caution. The two types of ear treatments were more or less on the same line. The effect of plant density was obvious: the lower plant density had a much higher regression coefficient, mainly because of the larger number of florets per ear, but probably also because of the larger individual kernel size; the intercept was also higher because of a greater cob yield. The regression coefficient and the intercept for the high plant density were comparable to the ones observed in experiment 1.

\section{Discussion}

Based on our results, we briefly discuss the possible effects of poor desynchronization, which are listed in the introduction of this article.

\section{Pollen shedding is already finished before (all) silks have emerged}

In most experiments, effects of covering and uncovering were only large for those silks that had yet to be extruded. This means that in general even a very low rate of pollen shedding is enough to pollinate all the silks. Only for the upper part of the ear, this may not be entirely true, but for this section grain set may be poor because of the competition with the advanced lower parts of the ear.

In early covering treatments, only some of the silks were exposed to pollen shedding. From the numbers of kernels one can learn something about the dynamics of silk emergence and pollen production.

Rates of silk emergence clearly differed among experiments. In experiment 1 , the maximum grain set was already reached very early, partly because there was protogyny, but also partly because the rate of silk emergence was high. From the covering treatments in experiments 2 and 3, it is obvious that the maximum was never reached, whereas the highest values observed for the proportion of grain set was more or less similar in the first three experiments.

In experiment 4 , the results of the high plant density were more or less similar to the ones observed in experiment 1: already when covering was delayed to day 5 , the grain set in the higher density reached its maximum. The maximum, however, was considerably lower than in the other experiments, probably due to the high temperatures during grain set (cf. Struik et al., 1986). For the lower density, the pollination 
had to last much longer to reach the maximum, because of the larger variation in time of silk extrusion associated with the larger ear (Table 1), but this maximum was much higher, partly because the lower plant density suffered less from the water shortage.

It is unlikely that the variation in response between years is caused by differences in amount of pollen. Probably the dynamics of silk emergence are different. Silk emergence is very sensitive to environmental conditions and is unlikely to occur when the temperatures during the day do not reach a certain value. For most genotypes this minimum growth temperature for silks is so high, that under Dutch conditions it may frequently happen, that the rate of silk emergence is slowed down.

\section{The amount of pollen is not adequate to pollinate all the silks}

Tassel treatments to reduce the amounts of pollen during pollination had hardly any effect on grain set, even though a much larger area was treated for each plot than finally used for the measurements. This shows that there was abundant lateral transport of pollen in this experiment.

The differences between the covering treatments and the uncovering treatments in their effects on the number of kernels in the lower parts of the ear at the same (low) duration of pollination show that the amount of pollen has a clear effect on the grain set.

From the uncovering treatments in experiment 3 , it can also be concluded that at least 10 days of pollination were necessary to reach maximum grain set, when only small amounts of pollen were available. If the amount of pollen was not adequate, grain set was scattered all over the ear, allowing individual kernels to become very large.

Results of experiment 4 did not prove any shortage of pollen, but in this experiment the covering did not last so long for the uncovering treatments.

\section{Silks are not receptive yet when pollen is shed}

We did not observe any lack of receptiveness of silks shortly after their extrusion. When ears were covered very early after the first silk emergence and pollination took place, a normal proportion of grain set was observed. Either the silks were already very receptive, or the pollen on the silks remained viable for such a long time that they could germinate, after the silks had become receptive.

\section{Silks are not receptive anymore when pollen is shed}

Even when ears were uncovered late, the proportion of grain set could still reach a considerable value. Although this may be partly due to the fact that plant-to-plant variability extends the period of availability of viable pollen, it also shows that silks remain receptive for quite a long time (up to 2 weeks), and that at the end of the pollination period a small amount of pollen can still realize abundant grain set.

Yet, some loss of receptiveness was observed in experiment 3, especially in the 


\section{P.C. STRUIK AND T. MAKONNEN}

lower ear parts. Receptiveness can also be a function of the competition between the different florets, as was shown for the upper ear part when the ears were uncovered early. Florets in the lower part of the ear can become weaker competitors by a delayed pollination because their advantage of early silk extrusion is lost and the disadvantage of longer silks becomes more important. This was visible in the drymatter partitioning within the ear in the uncovering treatments of the higher plant density of experiment 4 .

The effect of plant density on the number of kernels per ear was caused by an effect on the number of florets and the proportion of grain set. The positive effect of a delayed pollination on the number of kernels per ear, by an increase in the number of kernels in the upper part of the ear as observed in experiment 3, was not found in experiment 4 . This discrepancy was partly caused by the shorter period of covering in experiment 4 .

\section{Pollen is not viable when receptive silks are present}

Although loss of pollen viability cannot be ruled out as a cause of the poor kernel set in the treatments with the late uncovering, we think it did not play an important role in our experiments. In general, however, pollen has a short life-span after shedding. So, we observed effects on grain set because:

- not all silks were present yet at the time of pollination (early covering treatments in all experiments);

- pollen production was already low when silks were exposed to the pollen (uncovering treatments in experiment 3);

- silks were not fully receptive anymore when they were exposed to pollen (uncovering treatments in experiment 3 , especially the lower part of the ear);

- silks were not fully receptive because of fierce competition among florets.

Protogyny is unlikely to reduce grain set, because the silks can stay receptive very long. It may even have a positive effect. Protandry on the contrary, can reduce the grain set, especially of the silks of the upper florets, partly because these silks will be extruded too late, and partly because their florets are weak competitors.

\section{Acknowledgements}

We thank the teams of students who collected the data of experiments 2, 3 and 4 as part of their study at the Wageningen Agricultural University.

\section{References}

Bertin, Ch., A. Panouillé \& S. Rautou, 1976. Obtention de variétés de maïs 'profiliques en épis' productives en grain et à large adaptation écologique. Annales de l' Amélioration des Plantes 26: $387-418$.

Buren, L.L., J.J. Mock \& I.C. Anderson, 1974. Morphological and physiological traits in maize associated with tolerance to high plant density. Crop Science 14: $426-429$.

Dow, E.W., T.B. Daynard, J.F. Mildoon, D.J. Major \& G.W. Thurtell, 1984. Resistance to drought and density stress in Canadian and European maize (Zea mays L.) hybrids. Canadian Journal of Plant Science 64: 575 - 585. 
Duncan, W.G., W.A. Williams \& R.S. Loomis, 1967. Tassels and the productivity of maize. Crop Science 7: 37 - 39.

Fuchs, A., 1968. Beziehungen zwischen der Organogenese und der Ertragsbildung bei Zea mays. Zeitschrift für Pflanzenzüchtung 60: 260 - 283.

Hall, A.J., H.D. Ginzo, J.H. Lemcoff \& A. Soriano, 1980. Influence of drought during pollenshedding on flowering, growth and yield in maize. Zeitschrift für Acker- und Pflanzenbau 149: $287-298$.

Hall, A.J., F. Vilella, N. Trapani \& C.A. Chimenti, 1982. The effects of water stress and genotype on the dynamics of pollen-shedding and silking in maize. Field Crops Research 5: $349-363$.

Herrero, M.P. \& R.R. Johnson, 1981. Drought stress and its effects on maize reproductive systems. Crop Science 21: $105-110$.

Moss, G.I. \& L.A. Downey, 1971. Influence of drought stress on female gametophyte development in corn (Zea mays L.) and subsequent grain yield. Crop Science 11: $368-372$.

Muleba, N., T.G. Hart \& G.M. Paulsen, 1983. Physiological factors affecting maize (Zea mays L.) yields under tropical and temperate conditions. Tropical Agriculture (Trinidad) 60: $3-10$.

Phillips, I.D.J., 1975. Apical dominance. Annual Review of Plant Physiology 26: 341 - 367.

Sadras, V.O., A.J. Hall \& T.M. Schlichter, 1985a. Kernel set of the uppermost ear in maize: I. Quantification of some aspects of floral biology. Maydica 30: $37-47$.

Sadras, V.O., A.J. Hall \& T.M. Schlichter, 1985b. Kernel set of the uppermost ear in maize: II. A simulation model of effects of water stress. Maydica 30: $49-66$.

Snedecor, G.W. \& W.G. Cochran, 1980. Statistical methods. 7th edition. Iowa State University Press, Ames, Iowa, $507 \mathrm{pp}$.

Struik, P.C., 1982. The effects of switches in photoperiod on the reproductive development of temperate hybrids of maize. Netherlands Journal of Agricultural Science 30: 69 - 83.

Struik, P.C., 1983a. Effect of temperature on development, dry-matter production, dry-matter distribution and quality of forage maize (Zea mays L.). An analysis. Mededelingen Landbouwhogeschool Wageningen 83-3: $1-41$.

Struik, P.C., 1983b. Physiology of forage maize (Zea mays L.) in relation to its production and quality. Doctoral thesis, Wageningen Agricultural University, Wageningen, The Netherlands, 252 pp.

Struik, P.C., 1983c. The effects of switches in photoperiod on crop morphology, production pattern and quality of forage maize (Zea mays L.) under field conditions. Mededelingen Landbouwhogeschool Wageningen 83-2: 1 - 27.

Struik, P.C., 1983d. The effects of short and long shading, applied during different stages of growth, on the development, productivity and quality of forage maize (Zea mays L.). Netherlands Journal of Agricultural Science 31: 101 - 124.

Struik, P.C., M. Doorgeest \& J.G. Boonman, 1986. Environmental effects on flowering characteristics and kernel set of maize (Zea mays L.). Netherlands Journal of Agricultural Science 34: 469 $-484$.

Tollenaar, M. \& T.B. Daynard, 1978a. Kernel growth and development at two positions on the ear of maize (Zea mays L.). Canadian Journal of Plant Science 58: 189 - 197.

Tollenaar, M. \& T.B. Daynard, 1978b. Effect of defoliation on kernel development. Canadian Journal of Plant Science 58: 207 - 212. 